Article

\title{
Regulation of MicroRNA-155 and Its Related Genes Expression by Inositol Hexaphosphate in Colon Cancer Cells
}

\author{
Małgorzata Kapral *(D), Joanna Wawszczyk ${ }^{(D)}$ and Ludmiła Węglarz \\ Department of Biochemistry, Faculty of Pharmaceutical Sciences in Sosnowiec, Medical University of Silesia in \\ Katowice, Jedności 8, 41-200 Sosnowiec, Poland; jwawszczyk@sum.edu.pl (J.W.); lweglarz@sum.edu.pl (L.W.) \\ * Correspondence: mkapral@sum.edu.pl; Tel.: +48-32-364-12-61
}

Academic Editor: Ivana Vucenik

Received: 16 October 2019; Accepted: 14 November 2019; Published: 16 November 2019

\begin{abstract}
Inositol hexaphosphate (IP6), a natural dietary component, has been found as an antitumor agent by stimulating apoptosis and inhibiting cancer cell proliferation, their migration, and metastasis in diverse cancers including colon cancer. However, molecular mechanisms of its action have not been well understood. In recent years, microRNAs (miRNAs) have been reported to play important roles in a broad range of biologic processes, such as cell growth, proliferation, apoptosis, or autophagy. These small noncoding molecules regulate post-transcriptional expression of targets genes via degradation of transcript or inhibition of protein synthesis. Aberrant expression and/or dysregulation of miRNAs have been characterized during tumor development and progression, thus, they are potential molecular targets for cancer prevention. The aim of this study was to investigate the effect of IP6 on the miRNAs expression profile in Caco-2 colon cancer cells. 84 miRNAs were analyzed in Caco-2 cells treated with $2.5 \mathrm{mM}$ and $5 \mathrm{mM}$ IP6 by the use of PCR (Polymerase Chain Reaction) array. The effect of $5 \mathrm{mM} \mathrm{IP6}$ on selected potential miR-155 targets was determined by real-time (RT)-qPCR and ELISA (quantitative Polymerase Chain Reaction and Enzyme-Linked Immunosorbent Assay )method. The results indicated alteration in the specific 10 miRNA expression in human colon cancer cells following their treatment with $5 \mathrm{mM} \mathrm{IP6}$. It down-regulated 8 miRNAs (miR-155, miR-210, miR-144, miR-194, miR-26b, miR-126, miR-302c, and miR-29a) and up-regulated 2 miRNAs (miR-223 and miR-196b). In silico analysis revealed that FOXO3a, HIF-1 $\alpha$, and ELK3 mRNAs are those of predicted targets of miR-155. IP6 at the concentration of $5 \mathrm{mM}$ markedly induced FOXO3a and HIF-1a genes' expression at both mRNA and protein level and decreased the amount of ELK3 mRNA as well as protein concentration in comparison to the control. In conclusion, the present study indicates that one of the mechanisms of antitumor potential of IP6 is down-regulation of the miR-155 expression in human colon cancer cells. Moreover, the expression of genes that are targeted by miRNA are also modulated by IP6.
\end{abstract}

Keywords: IP6; miRNAs; miR-155; FOXO3a; HIF-1 $\alpha$; ELK3; colon cancer

\section{Introduction}

Chemoprevention is the use of natural, synthetic, or biologic chemical agents to suppress or to reverse the initial phase of carcinogenesis or to prevent carcinogenic progression to invasive cancer. Various epidemiological and preclinical studies have convincingly argued the role of some dietary agents, such as isoflavones, catechins, lycopene, or isothiocyanates, to be involved in preventing the occurrence of both solid and hematologic malignancies as well as their treatment $[1,2]$.

Inositol hexaphosphate (InsP6, IP6) is a natural fiber-associated dietary component mainly found in cereals, legumes, nuts, oil seeds, and wheat bran. It is a derivative of myo-inositol, of which 
all carbon atoms are bonded to phosphate groups [3,4]. In the last years, this phytochemical has attracted increasing attention and interest due to its wide range of health-beneficial effects. In many studies, IP6 has been shown to exert antioxidant, anti-inflammatory, and anti-aging effects in many biological systems. It participates in various vital cell functions such as signal transduction, RNA export, DNA repair, energy transduction, and ATP (Adenosine 5'-triphosphate) regeneration [5]. Furthermore, IP6 lowers serum cholesterol and triglycerides [6] as well as limits the formation of kidney stones [7]. However, IP6 is best appreciated for its anti-cancer properties, resulting from its capability of reduction cell proliferation, apoptosis induction, and tumor metastasis inhibition [8-10]. The outcomes of many experiments have shown that IP6 broad spectrum activities involve its impact on various intracellular signaling pathways, such as PI3K/AKT (Phosphatidylinositol-3 Kinase/AKT Serine/Threonine Kinase 1) [11,12] and expression of genes encoding key cellular proteins like p53, p21, p27, BCL-2, and MMPs [13-19]. The anti-cancer properties of dietary IP6 have previously been demonstrated by both in vitro and in vivo experimental cancer models including, prostate, breast, bladder, and colon $[10,12,13,15,16,19]$. Based on the above-mentioned IP6 properties, it could be considered as a good chemopreventive and chemotherapeutic agent. However, the molecular mechanisms underlying its biological activity still need to be investigated.

Over the past decades, the scientific investigation on microRNAs (miRNAs, miRs) has indicated their promising role in cancer diagnosis, target intervention, and cancer treatments. The short noncoding RNA containing approximately $22 \mathrm{nt}$, participate in the regulation of various cellular processes such as proliferation, differentiation, apoptosis, autophagy, and physiological metabolism. Generally, miRNAs regulate gene expression by binding to the $3^{\prime}$-untranslated region ( $3^{\prime}$ UTR) and also to the coding sequence of target mRNA, causing transcripts degradation or inhibition of their translation to functional proteins [20,21]. Currently, the existence of more than 1000 miRNAs has been estimated in human cells (comprising approximately $3 \%$ of all currently known genes in the human genome), which makes them one of the largest classes of gene expression regulators [22]. Importantly, each of the miRNAs can regulate hundreds or even thousands of target genes and, on the other hand, a single gene can be a target for multiple miRNAs [23]. The aberrant expression of miRNAs may evoke an increase in cell proliferation, invasiveness, angiogenesis, or inhibition of apoptosis, ultimately resulting in tumor formation. Therefore, they could function as oncogenes (miR-21, miR-155) or tumor suppressor genes (let-7, miR-15, miR-16) [22-27]. Taking this fact into account, the expression of specific miRNAs may provide valuable information for to prognostic and diagnostic purposes, and also propose them as emerging targets for cancer therapy. Many studies have shown that natural agents such as curcumin, resveratrol, isoflavone, and epigallocatechin-3-gallate could alter the expression of one or more miRNAs, leading to the modulation of their target genes' expression and then, the inhibition of cancer cell growth, induction of apoptosis, reversal of epithelial-mesenchymal transition, or enhancement of efficacy of conventional cancer therapeutics [28-31].

According to the broad spectrum of IP6 action, we hypothesize that IP6 may exert its anticancer properties, in part by altering the expression of miRNAs. Thus, the purpose of this study was to determine whether inositol hexaphosphate modifies the expression profile of miRNAs in Caco-2 human colon cancer cells as well as how it affects the expression of target genes of the selected miRNA molecule.

\section{Results}

\subsection{Cytotoxic Effect of Inositol Hexaphosphate (IP6) on Caco-2 Cells}

Lactate dehydrogenase (LDH) activity is widely used as a marker of drug or chemical cytotoxic properties. IP6-induced cell membrane damage was assessed by the LDH release assay. A dose-dependent cytotoxic effect of IP6 on Caco-2 cells was detected. LDH activity was very low in the control and cultures treated with IP6 at concentration up to $1 \mathrm{mM}$. The treatment of cells with IP6 at a concentration in the range of $2.5-10 \mathrm{mM}$ resulted in an increasing leakage of LDH out of the 
cells (Figure 1). Caco-2 exposed to $5 \mathrm{mM}$ and $10 \mathrm{mM}$ IP6 exhibited a significant increase in LDH release when compared to those treated with $2.5 \mathrm{mM} \mathrm{IP6}(p<0.001)$. A similar level of LDH in cultures stimulated with both $5 \mathrm{mM}$ and $10 \mathrm{mM}$ IP6 was observed ( $p=0.6645)$. Based on the results of this experiment, IP6 $2.5 \mathrm{mM}$ and $5 \mathrm{mM}$ concentrations were selected in the further experiments.

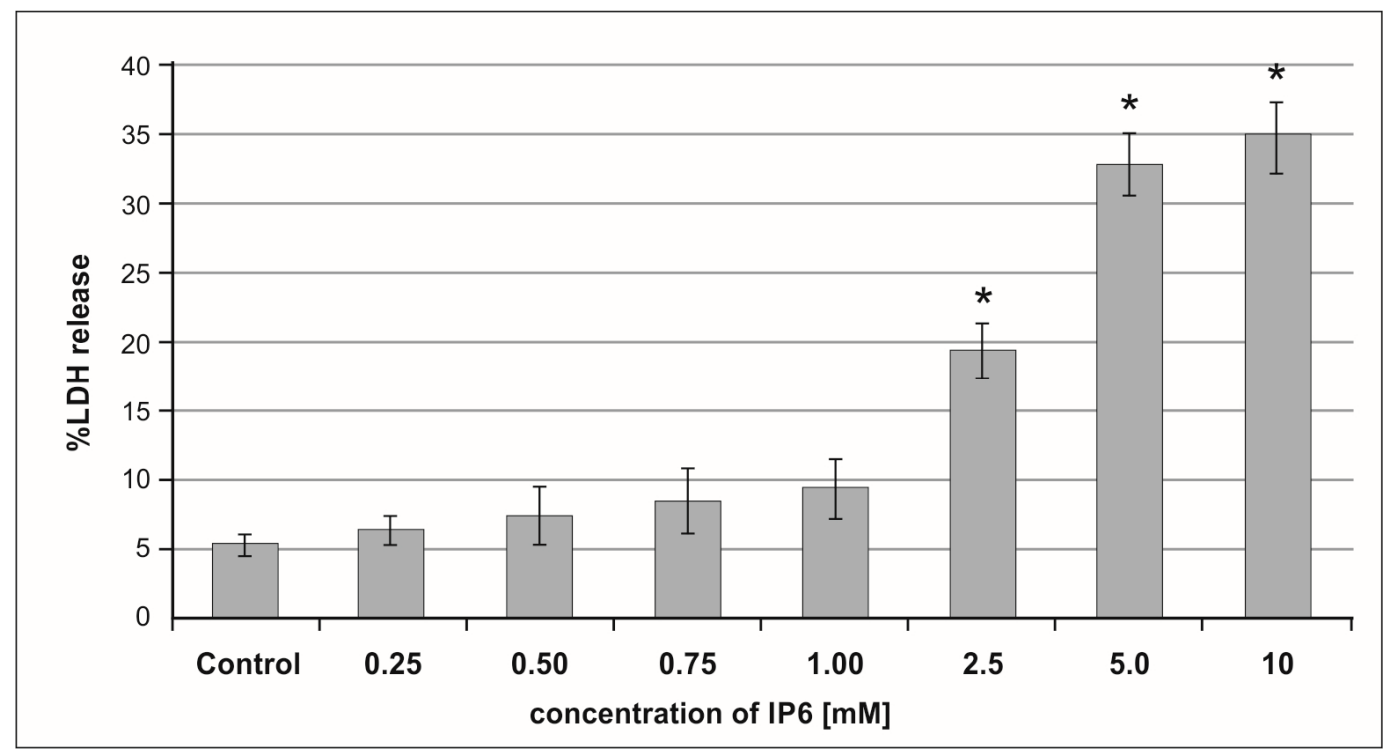

Figure 1. The effect of inositol hexaphosphate (IP6) on lactate dehydrogenase (LDH) release from Caco- 2 cells after $48 \mathrm{~h}$ of incubation. The results are presented as mean \pm standard deviation (SD) of six separate experiments, ${ }^{*} p<0.05$ compared with untreated controls.

\subsection{Effect of IP6 on MicroRNA (miRNA) Expression Profile in Caco-2 Cells}

Taking advantage of a commercially available PCR-based assay platform for profiling expression analysis, which relies on fluorescent detection of amplified products by the SYBR Green I dye, the 84 miRNAs expression profile in Caco-2 cells treated with IP6 was determined. At first, samples taken from the control and cells treated with $2.5 \mathrm{mM}$ and $5 \mathrm{mM}$ IP6 have been classified based on similarities in the global miRNA expression with the use of cluster analysis, and they appeared to cluster into two distinct groups. Caco-2 treated with $5 \mathrm{mM}$ IP6 clustered together, which indicates a different miRNA expression profile compared to the control and $2.5 \mathrm{mM}$ IP6-stimulated cells. On the contrary to $2.5 \mathrm{mM}$ IP6, its doubled concentration altered the expression of several miRNAs (Figure 2). In the next step of the analysis, miRNAs showing differential expression in Caco-2 exposed to $5 \mathrm{mM}$ IP6 were identified (Figure 3). We were able to point at 8 miRNAs which were differentially expressed in the two groups. Out of 84 miRNAs screened, based on two criteria (statistical significance and at least 2-fold change), 6 miRNAs were down-regulated and 2 miRNAs were upregulated by $5 \mathrm{mM} \mathrm{IP6}$, as compared to the untreated control (Table 1). The strongest change was observed in the case of miR-155, miR-210, and miR-223. The treatment of cells with $5 \mathrm{mM} \mathrm{IP6}$ resulted in about a 4-fold decreased expression of miR-155 and miR-210 as compared to the control. Furthermore, two miRNAs, i.e., miR-29a and miR-302c, showed a 1.9-fold reduction in expression in response to $5 \mathrm{mM}$ IP6. Simultaneously, $5 \mathrm{mM}$ IP6 stimulated the expression of $m i R-223$ and $m i R-196 b$ by 3.89- and 2.87-fold, respectively. 


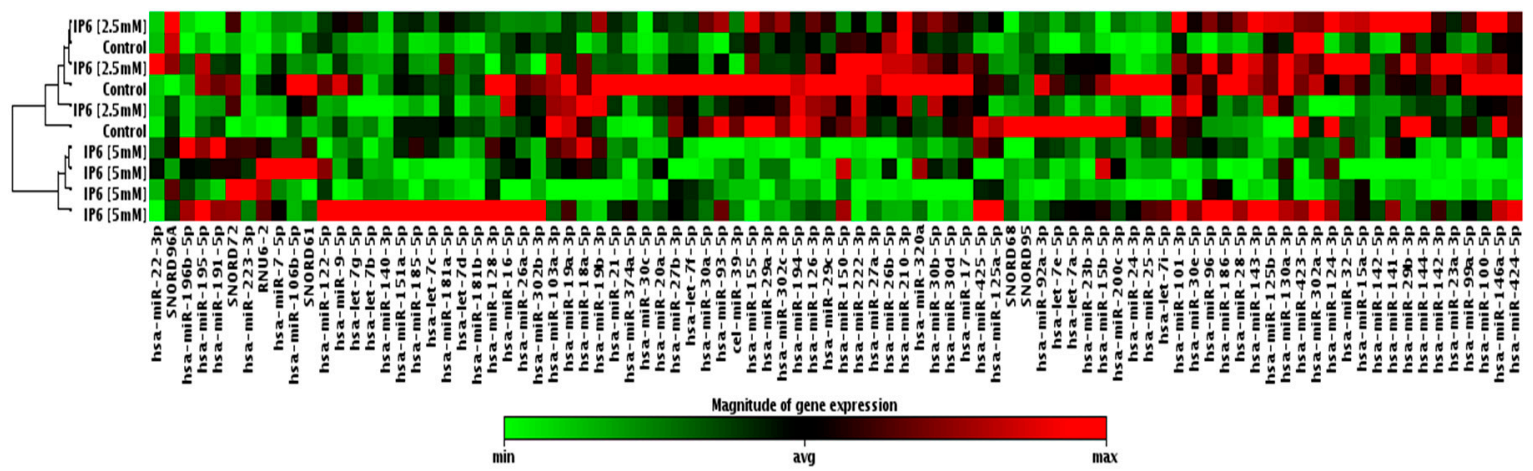

Figure 2. Clustergram and heatmap graph represents the expression level of 84 microRNAs (miRNAs) in untreated cells and Caco-2 treated with IP6 at concentrations of $2.5 \mathrm{mM}$ and $5 \mathrm{mM}$.

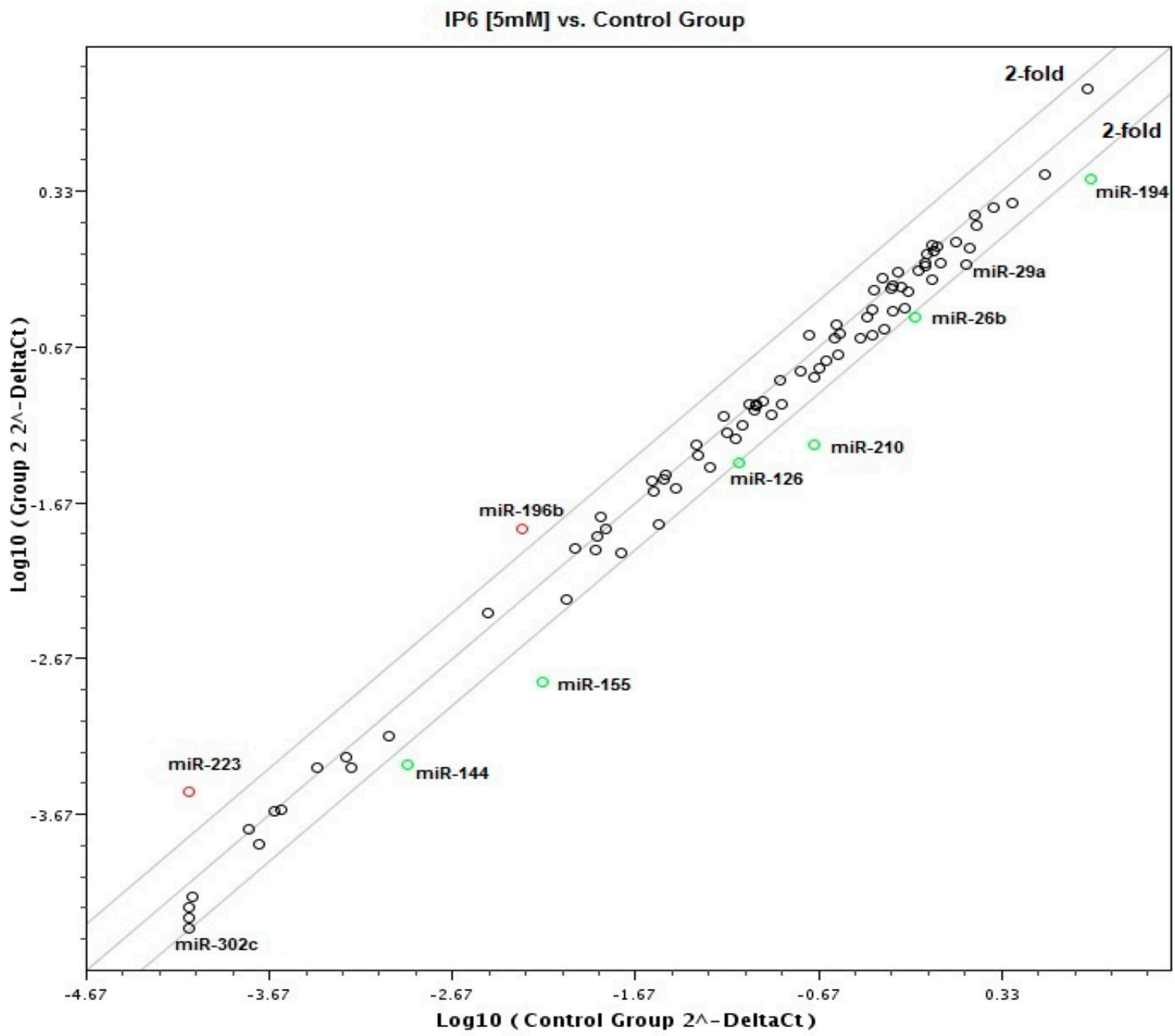

Figure 3. Scatter plots of miRNAs expression in untreated cells versus Caco-2 cells treated with $5 \mathrm{mM}$ IP6 ( $x$-axis represents the $2^{-\Delta C t}$ value of control cells, and y-axis represents the $2^{-\Delta C t}$ value of IP6-treated cells). The expression value of each human miRNA was plotted as a scatter plot, and threshold lines were drawn at a 2-fold expression change. 
Table 1. MicroRNA expression changes in Caco-2 cells treated with $5 \mathrm{mM}$ IP6 as compared with the control, as deduced from microRNA microarray analysis. Changes were considered significant for $p<0.05$.

\begin{tabular}{cccc}
\hline miRNA & Down/Up-Expression & Fold Change & $p$-Value \\
\hline$m i R-155$ & down-expression & -4.32 & 0.0013 \\
\hline$m i R-210$ & down-expression & -3.97 & 0.0025 \\
\hline$m i R-144$ & down-expression & -2.71 & 0.049 \\
\hline$m i R-194$ & down-expression & -2.54 & 0.0109 \\
\hline$m i R-26 b$ & down-expression & -2.17 & 0.0377 \\
\hline$m i R-126$ & down-expression & -2.03 & 0.0135 \\
\hline$m i R-302 c$ & down-expression & -1.93 & 0.011 \\
\hline$m i R-29 a$ & down-expression & -1.9 & 0.0197 \\
\hline$m i R-196 b$ & up-expression & 2.87 & 0.0187 \\
\hline$m i R-223$ & up-expression & 3.89 & 0.048 \\
\hline
\end{tabular}

In order to predict potential target genes for selected miRNAs, in silico analysis using TargetScan7.1 (http://www.targetscan.org/) was performed. This approach was based on the principle that miRNAs of target genes should contain miRNA's binding sites in their 3'-UTR (3'-Untranslated Region). The overall scoring of a miRNA binding site, denoted as the context score, depends on binding features, the localization of the binding site within the $3^{\prime} \mathrm{UTR}$, and the AU content of the area flanking the binding site [32]. The results of bioinformatics analysis revealed that there were 44 possible target genes for miR-210, 1043 possible target genes for $m i R-144,5593$ possible target genes for $m i R-126$, and 1045 possible target genes for miR-26b. The 364 and 412 possible target genes were detected for genes miR-196 and miR-223, respectively (data not shown).

Subsequently, we focused on miR-155, the microRNA that showed the highest change in expression in Caco-2 cells treated with $5 \mathrm{mM}$ IP6. In silico analysis indicated 552 genes whose 3'-UTR sequences contained tandem of predicted binding sites for miR-155 (Figures 4A, 5A and $6 \mathrm{~A}$ ). The following genes: H3F3A, TP53INP1, ETS1, FOS, FOXO3a, IKBKE, HIF-1A, ELK3, TGFBR2, IL6R, PIK3CA, and E2F2 have been found in this group (Table 2). 
Table 2. Selected predicted targets of $m i R-155-5 p$, as determined by TargetScan7.1.

\begin{tabular}{|c|c|c|c|}
\hline Target Gene & Gene Name & Number of Conserved Sites & Number of Poorly Conserved Sites \\
\hline ZNF385D & zinc finger protein $385 \mathrm{D}$ & 1 & 4 \\
\hline$H 3 F 3 A$ & H3 histone, family $3 \mathrm{~A}$ & 1 & 0 \\
\hline ETS1 & v-ets avian erythroblastosis virus E26 oncogene homolog 1 & 2 & 0 \\
\hline FOS & FBJ murine osteosarcoma viral oncogene homolog & 1 & 0 \\
\hline TCF4 & transcription factor 4 & 3 & 1 \\
\hline TP53INP1 & tumor protein p53 inducible nuclear protein 1 & 1 & 0 \\
\hline MAP3K10 & mitogen-activated protein kinase kinase kinase 10 & 1 & 0 \\
\hline SOCS1 & suppressor of cytokine signaling 1 & 1 & 0 \\
\hline SMAD1 & SMAD family member 1 & 1 & 0 \\
\hline KRAS & Kirsten rat sarcoma viral oncogene homolog & 1 & 1 \\
\hline FOXO3a & forkhead box O3a & 1 & 3 \\
\hline IKBKE & inhibitor of kappa light polypeptide gene enhancer in B-cells, kinase epsilon & 2 & 0 \\
\hline ELK3 & ELK3, ETS-domain protein (SRF accessory protein 2) & 1 & 1 \\
\hline$E 2 F 2$ & E2F transcription factor 2 & 2 & 0 \\
\hline RELA & v-rel avian reticuloendotheliosis viral oncogene homolog A & 1 & 0 \\
\hline PIK3CA & phosphatidylinositol-4,5-bisphosphate 3-kinase, catalytic subunit alpha & 1 & 0 \\
\hline HIF1A & hypoxia inducible factor 1, alpha subunit (basic helix-loop-helix transcription factor) & 1 & 1 \\
\hline SMAD5 & SMAD family member 5 & 1 & 1 \\
\hline IL6R & interleukin 6 receptor & 1 & 0 \\
\hline ELF4 & E74-like factor 4 (ets domain transcription factor) & 1 & 0 \\
\hline TGFBR2 & transforming growth factor, beta receptor II $(70 / 80 \mathrm{kDa})$ & 1 & 0 \\
\hline IRF2BP2 & interferon regulatory factor 2 binding protein 2 & 1 & 0 \\
\hline ADAM10 & ADAM metallopeptidase domain 10 & 1 & 0 \\
\hline GSK3B & glycogen synthase kinase 3 beta & 1 & 0 \\
\hline$S M A D 2$ & SMAD family member 2 & 1 & 1 \\
\hline
\end{tabular}


2.3. The Influence of IP6 on the Expression of Genes Encoding FOXO3a, HIF-1A, and ELK3 in Caco-2 Cells

In the next step of the study, the effect of $5 \mathrm{mM}$ IP6 on the expression of genes potentially modulated by miR-155 in Caco-2 cells has been evaluated. We selected three genes, i.e., FOXO3a, $H I F-1 \alpha$, and ELK3 that encode transcription factors. Expression of these genes was detected at both mRNA and protein levels. The results are presented in Figures 4-6. The exposure of the cells to IP6 at the concentrations of $5 \mathrm{mM}$ for $24 \mathrm{~h}$ resulted in an up-expression of FOXO3a and HIF-1 $a$ genes at both mRNA and protein levels, as compared with untreated cells (Figure 4B,C and Figure 5B,C). On the contrary, the treatment of cells with $5 \mathrm{mM}$ IP6 decreased the amount of ELK3 mRNA as well as protein concentration in comparison to the control (Figure 6B,C).

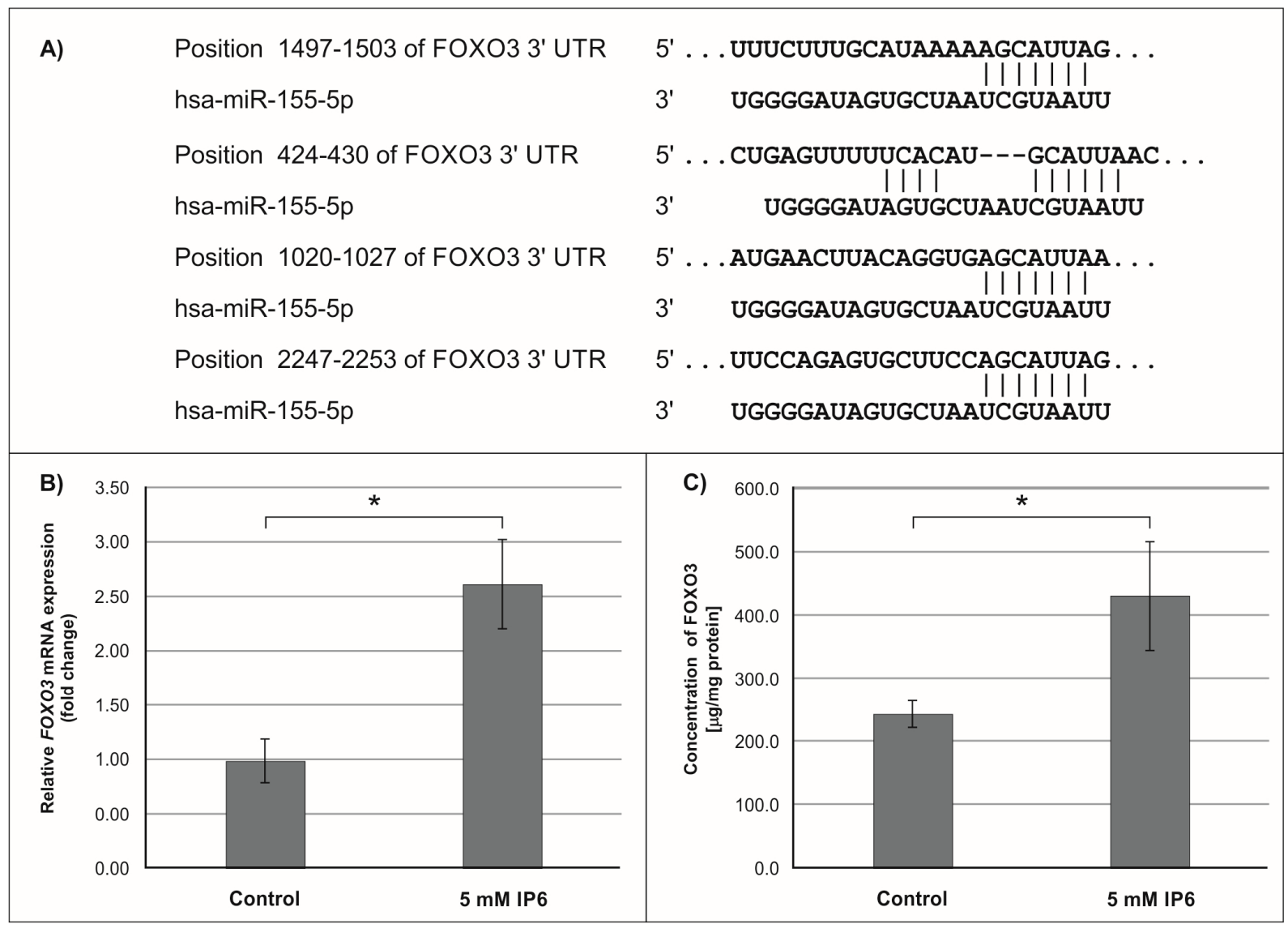

Figure 4. Effect of $5 \mathrm{mM}$ IP6 on FOXO3a gene expression in Caco-2 cells at $24 \mathrm{~h}$. (A) Schematic of the putative binding sites of miR-155-5p in 3'-UTR of FOXO3 mRNA, as determined by bioinformatics analysis. (B) Changes in FOXO3a mRNA expression in Caco-2 cells, as determined by RT-qPCR. (C) Changes in FOXO3a protein concentration in Caco-2 cells, as determined by ELISA test. The results are presented as mean $\pm \mathrm{SD}$ of three separate experiments; ${ }^{*} p<0.05$ versus control. 


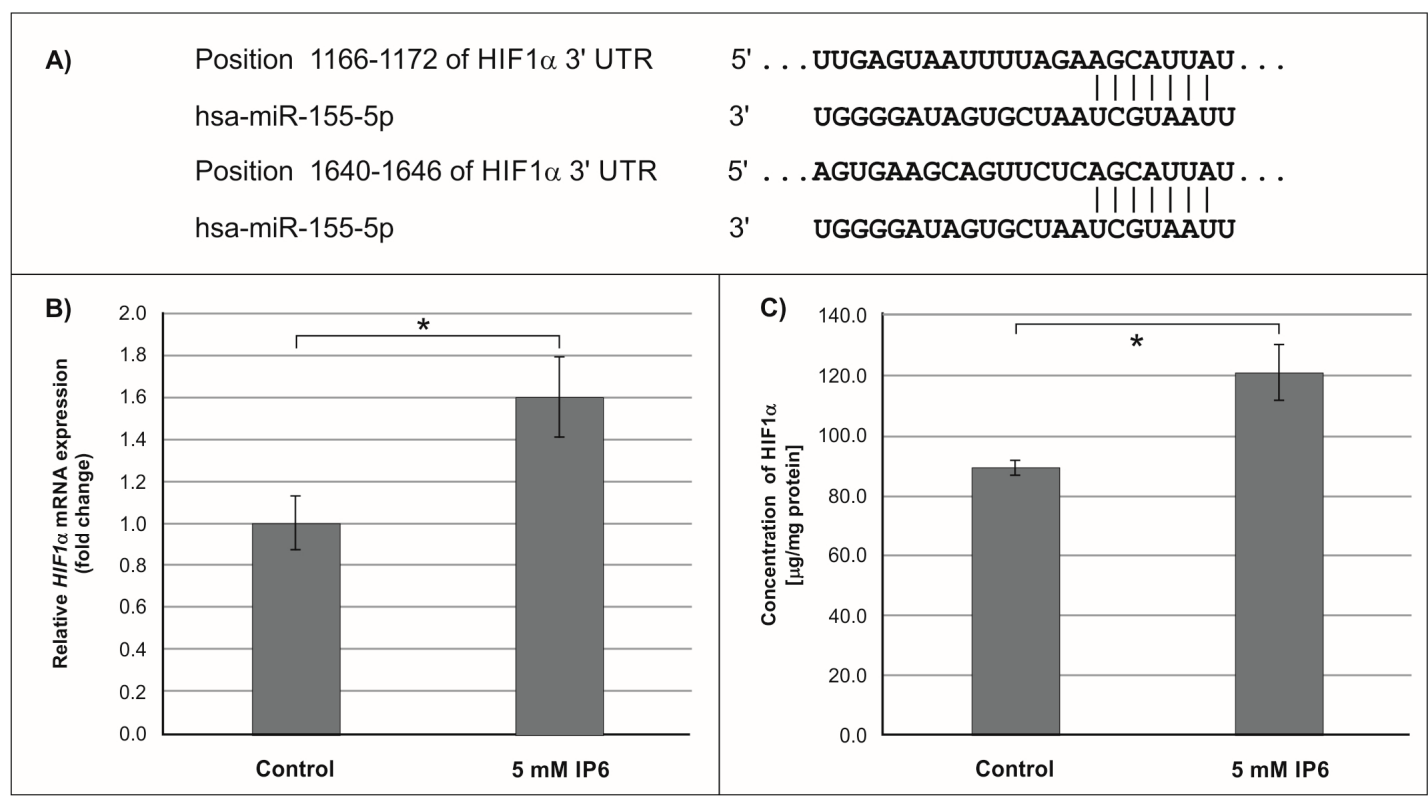

Figure 5. Effect of $5 \mathrm{mM}$ IP6 on HIF-1 $\alpha$ gene expression in Caco-2 cells at $24 \mathrm{~h}$. (A) Schematic of the putative binding sites of miR-155-5p in $3^{\prime}$-UTR of HIF- $1 \alpha$ miRNA, as determined by bioinformatics analysis. (B) Changes in HIF-1 $\alpha$ mRNA expression in Caco-2 cells, as determined by RT-qPCR. (C) Changes in HIF-1 $\alpha$ protein concentration in Caco- 2 cells, as determined by ELISA test. The results are presented as mean $\pm \mathrm{SD}$ of three separate experiments; ${ }^{*} p<0.05$ versus control.

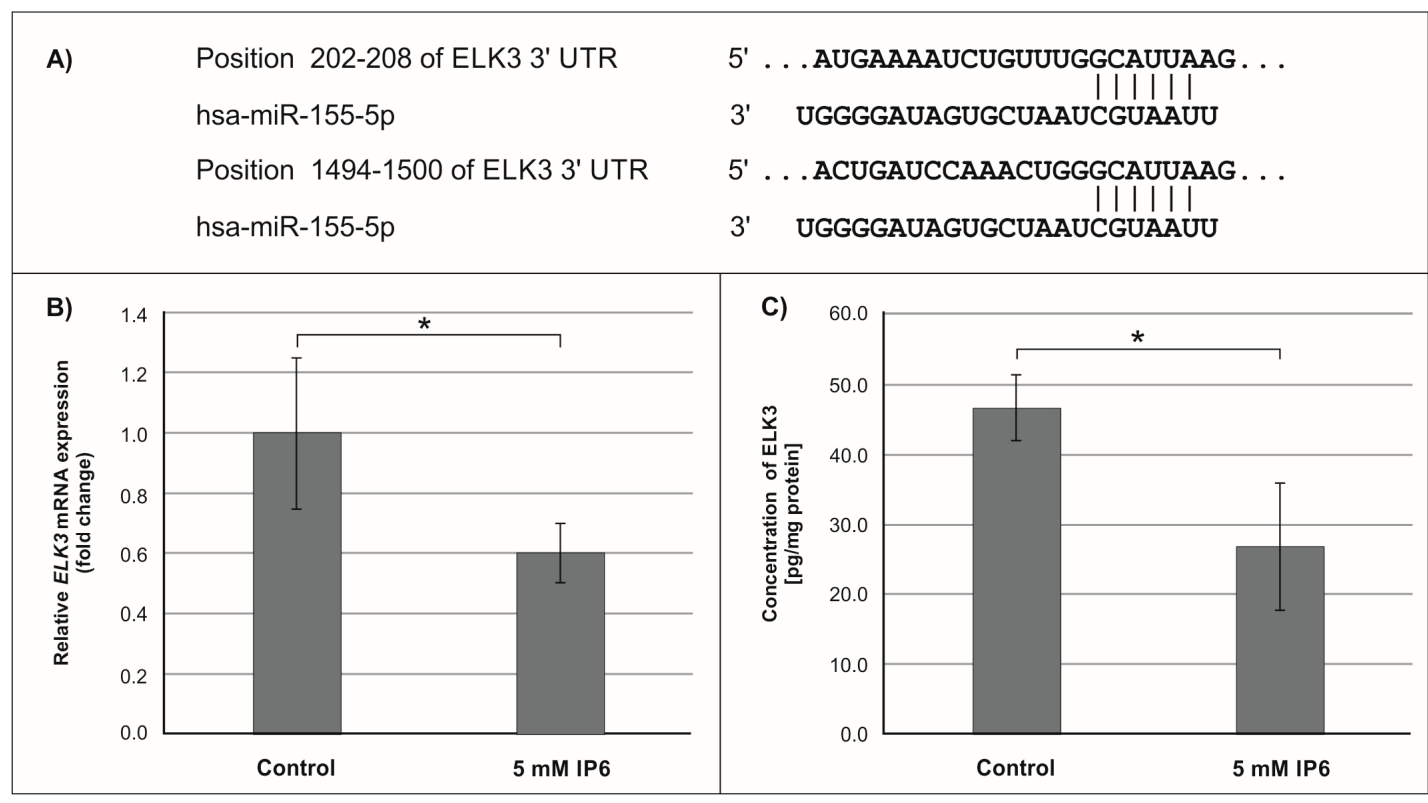

Figure 6. Effect of $5 \mathrm{mM}$ IP6 on ELK3 gene expression in Caco-2 cells at $24 \mathrm{~h}$. (A) Schematic of the putative binding sites of $m i R-155-5 p$ in 3'-UTR of ELK3 mRNA, as determined by bioinformatics analysis. (B) Changes in ELK3 mRNA expression in Caco-2 cells, as determined by RT-qPCR. (C) Changes in ELK3 protein concentration in Caco-2 cells, as determined by ELISA test. The results are presented as mean \pm SD of three separate experiments; ${ }^{*} p<0.05$ versus control.

\section{Discussion}

This study has provided significant evidence in the support of mechanisms elucidating the anticancer effect of inositol hexaphosphate. We found that IP6 can exert its biological activity via influence on the expression of some microRNAs which post-transcriptionally control the expression 
of related genes and consequently affect corresponding cellular processes. For the last few years, we have directed our attention to colorectal cancer (CRC), which is recognized as one of the most common malignant tumors of cancer-related deaths worldwide [33]. Among human cancers, CRC is a good candidate for chemoprevention due to the long precancerous stage before adenomas develop into cancer. Epidemiological studies have shown that consumption of a diet including fruits and vegetables is strongly associated with a reduced risk of colon cancer [34,35]. A large number of naturally occurring compounds isolated from plants have been shown to possess a possible anticancer activity [36]. The use of these agents is promising because they have minimal toxicity compared to conventional chemotherapy and they could influence multiple signaling pathways. Therefore, phytochemicals can be used alone or as an adjuvant in chemotherapy to improve therapeutic efficacy by overcoming drug resistance and reducing drug-induced toxicity $[37,38]$. Inositol hexaphosphate shows such characteristics. In vitro and in vivo studies demonstrated that IP6 targets cancer through multiple pathways and signaling molecules. It has been found to block protein kinases (e.g., phosphatidylinositol-3 kinase (PI3K), protein kinase C (PKC), protein kinase B (PKB) and mitogen-activated protein kinases (MAPK)), as well as to modulate transcriptional factors such as activating protein-1 (AP-1) and nuclear factor $\mathrm{KB}$ (NFkB) $[12,16,19,39]$.

During the last several years, an increasing number of reports have documented the key role of miRNAs in the regulation of many cellular processes by controlling protein synthesis. miRNAs can act directly on the target miRNA or indirectly by regulating intermediate components, such as genes that encode transcription factors, which in turn control the expression of various genes [40]. Phuah and Nagoor [38] conclude that, as natural agents exert their anticancer effects by targeting multiple signaling pathways, and miRNAs regulate diverse biological processes including cell proliferation and programmed cell death, it is thought that miRNAs could play a role in regulating the response towards natural agents. The strategies for the regulation of miRNAs in cancer could allow the inactivation of oncogenic miRNAs, activation of tumor suppressor miRNAs, and targeting specific miRNAs to restore drug sensitivity [37].

The aim of the present study was to examine whether microRNAs could be involved in the response of colon cancer cells to the treatment with inositol hexaphosphate. To the best of our knowledge, the influence of IP6 on the miRNAs expression in human colon cancer cells has not been evaluated, as yet.

To determine the effect of IP6 on the miRNA profile expression in colon cancer, Caco-2 cells were incubated with $2.5 \mathrm{mM}$ and $5 \mathrm{mM}$ of IP6 for $24 \mathrm{~h}$. As observed in this study, $2.5 \mathrm{mM}$ IP6 had no influence on miRNAs expression, while $5 \mathrm{mM}$ IP6 (a concentration corresponding to its physiological amount in the human large gut reaching $4 \mathrm{mM}$ [41]) altered the expression of 10 miRNAs. Among them, 2 miRNAs were up-regulated (miR-223 and miR-196b) and 8 were down-regulated (miR-155, miR-210, miR-144, miR-194, miR-26b, miR-126, miR-302c, and miR-29a). Importantly, miR-155 was the most down-regulated miRNA in cells exposed to IP6. Therefore, in the next step of the study, we focused on miR-155 and evaluated how IP6 affected three selected target transcripts of this molecule (FOXO3a, HIF-1 $\alpha$, and ELK3).

The miR-155 is recognized as a multifunctional microRNA. Since it is known to target many transcripts including those encoding transcription factors, cytokines, and enzymes, it may be involved in the control of several cellular processes, such as cell growth and survival, cell migration and invasion, cell adhesion junction, apoptosis, and proliferation [42-44]. Consequently, this small molecule plays a pivotal role as an oncogenic miRNA in tumorigenesis and cancer progression. The results of many studies showed an increased expression of miR-155 in various cancers, including colon cancer [25,44-46]. An elevated miR-155 level was accompanied by down-regulation of its target gene transcripts and resulted in inhibition of translation process. Liu et al. [45] observed that upregulating the expression of miR-155 in SW-480 colorectal cancer cells promoted distant invasion and metastasis of tumor cells through activating the Wnt/ $\beta$-catenin signal pathway. Additionally, it has been shown to be involved in TGF- $\beta / S M A D-i n d u c e d$ epithelial-mesenchymal transition (EMT) [47]. Moreover, a number 
of target genes of miR-155 affect other cancer-related processes, such as cell growth and survival (CCND1 and GAB3), cell adhesion junction (ANKRD6 and SMAD2), proliferation (SOCS1 and STAT3), and apoptosis (TP53BP1) [42,48]. The published data also suggested that miR-155 may influence inflammation-induced development of cancer [29,49,50]. Recently, O'Connell and co-workers [51] reported that miR-155 targets inositol phosphatase (SHIP), the enzyme that cleaves phosphatidylinositol (3,4,5)-trisphosphate $\left(\mathrm{PIP}_{3}\right)$ to generate phosphatidylinositol 3,4-bisphosphate (PI 3,4-P 2 ), i.e., the factor implicated in the regulation of kinase AKT activity.

Furthermore, miR-155 exerts its oncogenic function by targeting critical suppressor genes, such as FOXO3a. FOXO3a (FOXO3) is a member of the forkhead box class O (FOXO) subfamily of transcription factors that mediate a variety of cellular processes including apoptosis, proliferation, cell cycle progression, and DNA damage. FOXO3 induces cell cycle arrest mediated through transcription of multiple cell cycle kinase inhibitors (CKI), such as p27 (CDKN1B) and p21 (CDKN1A). It is also involved in the regulation of autophagy in cancer cells. FOXO3a acts as a tumor suppressor and it is frequently inactivated in cancer cells, which is followed by the initiation and progression of cancer [52,53]. FOXO3a is directly targeted by miR-155, which blocks translation of this factor. Experimental studies revealed that the overexpression of miR-155 down-regulates the expression of FOXO3a protein. Indeed, Gao et al. [54] revealed that overexpression of miR-155 in colon cancer tissues and human colon cancer cell lines (HT29 and SW620) was associated with decreased levels of FOXO3a. In addition, their study showed that $m i R-155$ may not only promote colon cancer growth but also increase colon cancer chemo-resistance to cisplatin through inhibiting FOXO3a expression. So, reduction of miR-155 expression is a potential interest of the search for chemopreventive and chemotherapeutical agents. The findings of this study revealed that IP6 decreased the expression of miR-155 in colon cancer cells, which was accompanied by up-regulated expression of the FOXO3a gene at both miRNA and protein levels.

Hypoxia-inducible factor $1 \alpha(H I F-1 \alpha)$ is one of the subunits of hypoxia-inducible factor 1 (HIF-1) [55]. HIF-1 is an oxygen-dependent transcriptional activator. More than 60 putative HIF-1 target genes have been identified. The target genes of HIF-1 are especially related to angiogenesis and cell proliferation/survival. HIF-1 regulates the expression of all enzymes of the glycolytic pathway, as well as the expression of the glucose transporters GLUT1 and GLUT3, which mediate cellular glucose uptake. HIF-1 $\alpha$ also plays a role in many diseases, such as cancer, that generate a hypoxic microenvironment [55,56]. The in vitro studies by Robertson et al. [57] revealed that miR-155-5p specifically down-regulated HIF-1 $\alpha$. The results of our study demonstrated that in Caco- 2 cells treated with $5 \mathrm{mM}$ IP6, the amount of both transcript and protein of HIF-1 $\alpha$ slightly increased in comparison to the control. This may suggest that such an effect was caused by IP6-reduced miR-155 expression.

The oncogenic miR-155 can also control the expression of ELK3 miRNA, of which two conserved miR-155-5p target sites in the 3'-UTR of ELK3 have been identified [57]. ELK3 belongs to the ETS transcriptional factors family (domain-containing protein ETS) and it participates in MAPK kinase signaling. It represses the transcription of the protooncogene c-Fos. Overexpression of ELK3 has been shown to inhibit proliferation of cancer cells. This factor is also involved in the hypoxia response, angiogenesis, and vascular integrity. Although ELK3 functions as a transcriptional repressor, it can be transformed into a transcriptional activator via RAS/ERK signaling [57-59]. Earlier published data have shown that, in vein endothelial (HUVEC) cells ELK3, miRNA was down-regulated by miR-155, which also significantly decreased ELK3 protein levels, whereas the miR-155 inhibitor increased ELK3 levels to a small extent [57]. Our study demonstrated that both ELK3 miRNA and protein amounts were decreased in IP6-treated cells, in which miR-155 was down-regulated. Therefore, we can conclude that this change in ELK3 gene expression was independent of the regulatory effect of IP6 on miR-155. Perhaps, in Caco-2 colon cancer cells, other specific microRNAs may be able to regulate ELK3 miRNA expression at the post-transcriptional level.

In our previous studies, we analyzed the effect of IP6 on Caco-2 colon cancer cells proliferation and apoptosis. We have shown that IP6 reduce proliferation and induce apoptosis of Caco-2 through 
the inhibition of the AKT/mTOR pathway and the mTOR effector, followed by modulation of the expression and activity of several key components of this pathway. Furthermore, IP6 regulated the expression of cyclin D1 and increased the level of p21 protein, cyclin-dependent kinase inhibitor, in Caco-2 cells. Concomitantly, IP6 induced apoptosis of colon cancer cells, which was accompanied by upregulated expression of caspase 9 and caspase 3 at the transcriptional level as well as an increase in caspase-3 activity $[19,60]$. Numerous studies have revealed that transcriptional factor FOXO3 regulates the expression of genes encoding p21, p27, cyclin D1, and caspases. On the other hand, miRNA-155 negatively regulates the expression of $F O X O 3$. The findings described herein indicate that IP6 at the concertation of $5 \mathrm{mM}$ alters specific miRNAs' expression in Caco-2 cells. To the best of our knowledge, the effect of IP6 on the miRNA's expression in human colon cancer cells is demonstrated for the first time. Furthermore, gene expression that is targeted by these IP6-regulated specific miRNAs was also modulated by this compound. Hence, it can be suggested that antitumor activity of IP6 may be due to its effect on miRNA-related changes in cancer cells.

In conclusion, the present study illustrates, for the first time, that IP6 exerts its biological functions by down-regulating the miR-155 expression in human colon cancer cells. Further studies are warranted to investigate the interaction between IP6 and other differently expressed miRNAs, and their target miRNAs, which may provide new perspectives on understanding the anticancer and chemopreventive effect of inositol hexaphosphate.

\section{Materials and Methods}

\subsection{Cell Culture}

The human colon cancer cell line Caco-2 was purchased from American Type Tissue Collection (ATCC) (Rockville, MD, USA). The cells were grown routinely in RPMI 1640 medium (Sigma-Aldrich, St. Louis, MO, USA) supplemented with $10 \%$ fetal bovine serum (BioWest, Nuaillé, France), 100 U/mL penicillin, $100 \mu \mathrm{g} / \mathrm{mL}$ streptomycin (Sigma Aldrich), and $10 \mathrm{mM}$ HEPES (Sigma Aldrich) in a humidified atmosphere of $5 \% \mathrm{CO}_{2}$ at $37^{\circ} \mathrm{C}$. Cells were treated with IP6 and proceeded for analysis, as described below.

\subsection{Inositol Hexaphosphate (IP6)}

IP6 (dipotassium salt) was purchased from Sigma-Aldrich. IP6 was dissolved in distilled water to make a $250 \mathrm{mM}$ stock solution and adjusted to $\mathrm{pH}$ 7.4. Subsequently, it was diluted in tissue culture media to the desired concentrations of $0.25,0.5,0.75,1,2.5,5$, and $10 \mathrm{mM}$.

\subsection{Lactate Dehydrogenase (LDH) Assay}

Leaky membranes of damaged or dead cells release the lactate dehydrogenase (LDH) into the culture medium. Increased LDH activity in the supernatants of cell cultures correlates with the percentage of dead cells. The cytotoxic effect of IP6 was analyzed by LDH release into the culture medium with the use of an In Vitro Toxicology Assay Kit, Lactate Dehydrogenase-Based (Sigma-Aldrich). The assay was performed according to the manufacturer's protocol. Cells were seeded in 96-well plates at an initial density of $1 \times 10^{4}$ cells per well in $200 \mu \mathrm{L}$ culture medium and incubated for $24 \mathrm{~h}$. Afterwards, the medium was aspirated and cells were exposed to the freshly prepared media containing various concentrations of IP6 $(0.25-10 \mu \mathrm{M})$. After $48 \mathrm{~h}$, LDH activity was determined both in the culture medium (extracellular LDH activity) and in the cell lysates (total LDH activity). The absorbance was measured at $492 \mathrm{~nm}$ and $690 \mathrm{~nm}$ (reference wavelength) using the Labtech LT-5000 microplate reader (Uckfield, UK). The results are shown as a percentage of total LDH released into the medium. Subsequently, the percentage of liberated enzyme was calculated for control cells and cells treated with IP6 using the following equation: LDH release $(\%)=$ extracellular LDH/total $\mathrm{LDH} \times 100 \%$. The experiment was repeated six times. 


\section{4. microRNA Isolation and microRNA Polymerase Chain Reaction Arrays}

For miRNA expression studies, Caco-2 cells were seeded into six-well plates (Nunc International, Rochester, NY, USA) at a density of $4.5 \times 10^{5}$ per well and allowed to grow to confluency in $3 \mathrm{~mL}$ of medium. After 3 days, the culture media were changed to media with $2 \%$ FBS (Fetal bovine serum) and cells were then cultured for 2 days. Afterwards, cells were treated with 2.5 and 5 mM IP6 for $24 \mathrm{~h}$. The untreated Caco-2 cells were used as the control. Small RNAs were extracted from the control and IP6-treated cells by the use the QIAzol and miRNeasy Mini Kit (Qiagen Inc., Valencia, CA, USA) following the manufacturer's protocol. The concentration of RNA samples was determined spectrophotometrically on the basis of absorbance values at a wavelength of 260 using a Shimadzu UV-1800 spectrophotometer (Shimadzu, Kyoto, Japan). RNA purity was judged by the ratio of absorbances at 260 and $280 \mathrm{~nm}$ (A260/A280) (ratios between 1.9 and 2.1 were acceptable). For each reaction, $25 \mathrm{ng}$ of RNA, extracted from control and cells treated with 2.5 and $5 \mathrm{mM}$ IP6, was submitted to reverse transcription with miScript II RT Kit (Qiagen) following the manufacturer's instructions (Qiagen). The reverse transcription (RT) reaction was carried out at $37^{\circ} \mathrm{C}$ for $60 \mathrm{~min}$, and then the samples were heated at $95^{\circ} \mathrm{C}$ for $5 \mathrm{~min}$ to inactivate the reverse transcriptase. To measure miRNAs, cDNA was diluted in RNase-free water. The profile expression of the 84 most abundantly expressed and best characterized miRNAs in miRBase was performed using the Human miFinder miScript miRNA PCR Array (MIHS-001Z) and miScript SYBR Green PCR Kit (Qiagen), according to the manufacturer's protocol. Real-time qPCR analysis was done on a CFX Connect Real-Time PCR Detection System (Bio-Rad, Hercules, CA, USA) under the following conditions: $95^{\circ} \mathrm{C}$ for $15 \mathrm{~min}$ and 40 cycles at $94{ }^{\circ} \mathrm{C}$ for $15 \mathrm{~s}, 55^{\circ} \mathrm{C}$ for $30 \mathrm{~s}, 70{ }^{\circ} \mathrm{C}$ for $30 \mathrm{~s}$. Specificity of PCR reaction was confirmed by determining the temperature of melting for all amplimers. The relative amount of each miRNA in the PCR array analysis was normalized to an average of four small nuclear housekeeping genes (SNORD 61, SNORD 68, SNORD 72, and SNORD 96A). The fold-change for each miRNA in IP6-treated cells relative to control cells was calculated using the $2^{-\Delta \Delta C T}$ method. miRNAs were considered as potentially differing if $p<0.05$ and at least a 2-fold change in the mean expression level between cells treated with IP6 and controls was found. The results were collected from three or four independent experiments.

\subsection{Total RNA Extraction and Quantitative Real-Time RT-PCR (RT-qPCR)}

To evaluate transcriptional activity of FOXO3a, HIF-1 $\alpha$, and ELK3 genes, the cells were seeded at a density of $8 \times 10^{5}$ onto $21.5 \mathrm{~cm}^{2}$ culture dishes (Nunc International). Then, IP6 at the concentration of $5 \mathrm{mM}$ was added to cell cultures for $24 \mathrm{~h}$. Total RNA was extracted from the cells with the use of TRI REAGENT (Zymo Research, Irvine, CA, USA). Detection of the expression of examined genes was carried out using a RT-qPCR technique with a SYBR Green chemistry (SYBR Green Quantitect RT-PCR Kit) (Qiagen), as was described previously [19]. Primers for FOXO3a, HIF-1 $\alpha$, and ELK3 mRNAs were commercially available (Sigma-Aldrich). The expression levels of all genes in cultured cells were expressed as the fold change (FC) relative to the corresponding controls. FC values greater than one indicate a positive or an up-regulation. FC values less than one indicate a negative or down-regulation.

\subsection{Measurement of FOXO3A, HIF-1 $\alpha$, and ELK3 Proteins}

Expression of FOXO3a, HIF-1 $\alpha$, and ELK3 proteins in Caco-2 cells was determined by commercially available enzyme-linked immunosorbent assay (ELISA) kits (Cloud-Clone Corp. Houston, TX, USA and Cusabio Houston, TX, USA). Cells were plated onto $100 \mathrm{~mm}$ dishes at a density of $3 \times 10^{6}$ cells. After two days, the media were aspirated and cells were incubated with IP6 at the concentration of $5 \mathrm{mM}$ for $24 \mathrm{~h}$. Subsequently, cells were lysed in commercially available lysis buffer. The concentrations of FOXO3A, HIF-1 $\alpha$ and ELK3 proteins in cell lysates were measured with ELISA kits following the manufacturers' protocols. Results are normalized to total cellular protein content, which was determined by the Bradford's method (Sigma-Aldrich). 


\subsection{Statistical Analyses}

Statistical analysis was performed with the use of Statistica PL 12.0 software. All data expressed as means \pm standard deviation (SD) were representative of at least three independent experiments. Comparison of more than two datasets was performed by one-way analysis of variance (ANOVA) followed by a post-hoc Tukey test. Comparison of two datasets was performed by an unpaired t-test. The significance level was assumed for $p<0.05$. PCR array analysis of miRNA expression was performed using SABiosciences' web-based software (http://pcrdataanalysis.sabiosciences.com/mirna.).

Author Contributions: M.K. designed the research and wrote the paper; M.K. and J.W. carried out the experiments, M.K. performed the statistical analysis; M.K. and J.W. analyzed and interpreted the data; and L.W. revised the manuscript critically for important intellectual content. All authors read and approved the final version of this manuscript.

Funding: This research was funded by grants No. KNW-1-090/K/8/I, KNW-1-018/K/7/I from the Medical University of Silesia (Katowice, Poland).

Conflicts of Interest: The authors declare no conflict of interest.

\section{References}

1. Ranjan, A.; Ramachandran, S.; Gupta, N.; Kaushik, I.; Wright, S.; Srivastava, S.; Das, H.; Srivastava, S.; Prasad, S.; Srivastava, S.K. Role of phytochemicals in cancer prevention. Int. J. Mol. Sci. 2019, $20,4981$. [CrossRef] [PubMed]

2. Raimondi, L.; de Luca, A.; Giavaresi, G.; Barone, A.; Tagliaferri, P.; Tassone, P.; Amodio, N. Impact of natural dietary agents on multiple myeloma prevention and treatment: Molecular insights and potential for clinical translation. Curr. Med. Chem. 2018. [CrossRef] [PubMed]

3. Vucenik, I.; Shamsuddin, A.M. Cancer Inhibition by inositol hexaphosphate (IP6) and inositol: From laboratory to clinic. J. Nutr. 2003, 133, 3778S-3784S. [CrossRef] [PubMed]

4. Vucenik, I.; Shamsuddin, A.M. Protection against cancer by dietary IP6 and inositol. Nutr. Cancer 2006, 55, 109-125. [CrossRef]

5. Matejuk, A.; Shamsuddin, A. IP6 in cancer therapy: Past, present and future. Curr. Cancer Ther. Rev. 2010, 6, 1-12. [CrossRef]

6. Jariwalla, R.J. Inositol hexaphosphate (IP6) as an anti-neoplastic and lipid-lowering agent. Anticancer Res. 1999, 19, 3699-3702.

7. Grases, F.; Costa-Bauzá, A. Phytate (IP6) is a powerful agent for preventing calcifications in biological fluids: Usefulness in renal lithiasis treatment. Anticancer Res. 1999, 19, 3717-3722.

8. Singh, R.P.; Agarwal, C.; Agarwal, R. Inositol hexaphosphate inhibits growth, and induces G1 arrest and apoptotic death of prostate carcinoma DU145 cells: Modulation of CDKI-CDK-cyclin and pRb-related protein-E2F complexes. Carcinogenesis 2003, 24, 555-563. [CrossRef]

9. Fu, M.; Song, Y.; Wen, Z.; Lu, X.; Cui, L. Inositol hexaphosphate and inositol inhibit colorectal cancer metastasis to the liver in BALB/c mice. Nutrients 2016, 8, 286. [CrossRef]

10. Bizzarri, M.; Dinicola, S.; Bevilacqua, A.; Cucina, A. broad spectrum anticancer activity of myo-inositol and inositol hexakisphosphate. Int. J. Endocrinol. 2016, 2016, 5616807. [CrossRef]

11. Gu, M.; Roy, S.; Raina, K.; Agarwal, C.; Agarwal, R. Inositol hexaphosphate suppresses growth and induces apoptosis in prostate carcinoma cells in culture and nude mouse xenograft: PI3K-Akt pathway as potential target. Cancer Res. 2009, 69, 9465-9472. [CrossRef] [PubMed]

12. Liu, G.; Song, Y.; Cui, L.; Wen, Z.; Lu, X. Inositol hexaphosphate suppresses growth and induces apoptosis in HT-29 colorectal cancer cells in culture: PI3K/Akt pathway as a potential target. Int. J. Clin. Exp. Pathol. 2015, 8, 1402-1410. [PubMed]

13. Agarwal, C.; Dhanalakshmi, S.; Singh, R.P.; Agarwal, R. Inositol hexaphosphate inhibits growth and induces G1 arrest and apoptotic death of androgen-dependent human prostate carcinoma LNCaP cells. Neoplasia 2004, 6, 646-659. [CrossRef] [PubMed]

14. Kandzari, S.J.; Riggs, D.; Jackson, B.; Luchey, A.; Oliver, C.; Zaslau, S. In vitro regulation of cell growth and angiogenesis by inositol hexaphosphate in bladder cancer. Curr. Urol. 2013, 6, 199-204. [CrossRef] [PubMed] 
15. Tantivejkul, K.; Vucenik, I.; Shamsuddin, A.M. Inositol hexaphosphate (IP6) inhibits key events of cancer metastasis: I. In vitro studies of adhesion, migration and invasion of MDA-MB 231 human breast cancer cells. Anticancer Res. 2003, 23, 3671-3679.

16. Vucenik, I.; Ramakrishna, G.; Tantivejkul, K.; Anderson, L.M.; Ramljak, D. Inositol hexaphosphate (IP6) blocks proliferation of human breast cancer cells through a PKCdelta-dependent increase in p27Kip1 and decrease in retinoblastoma protein ( $\mathrm{pRb})$ phosphorylation. Breast Cancer Res. Treat. 2005, 91, 35-45. [CrossRef] [PubMed]

17. Weglarz, L.; Molin, I.; Orchel, A.; Parfiniewicz, B.; Dzierzewicz, Z. Quantitative analysis of the level of p53 and p21(WAF1) mRNA in human colon cancer HT-29 cells treated with inositol hexaphosphate. Acta Biochim. Pol. 2006, 53, 349-356.

18. Roy, S.; Gu, M.; Ramasamy, K.; Singh, R.P.; Agarwal, C.; Siriwardana, S.; Sclafani, R.A.; Agarwal, R. p21/Cip1 and p27/Kip1 are essential molecular targets of inositol hexaphosphate for its antitumor efficacy against prostate cancer. Cancer Res. 2009, 69, 1166-1173. [CrossRef]

19. Kapral, M.; Wawszczyk, J.; Jesse, K.; Paul-Samojedny, M.; Kuśmierz, D.; Węglarz, L. Inositol hexaphosphate inhibits proliferation and induces apoptosis of colon cancer cells by suppressing the AKT/mTOR signaling pathway. Molecules 2017, 22, 1657. [CrossRef]

20. Bartel, D.P. MicroRNAs: Genomics, biogenesis, mechanism, and function. Cell 2004, 116, 281-297. [CrossRef]

21. Filipowicz, W.; Jaskiewicz, L.; Kolb, F.A.; Pillai, R.S. Post-transcriptional gene silencing by siRNAs and miRNAs. Curr. Opin. Struct. Biol. 2005, 15, 331-341. [CrossRef] [PubMed]

22. Cummins, J.M.; Velculescu, V.E. Implications of micro-RNA profiling for cancer diagnosis. Oncogene 2006, 25, 6220-6227. [CrossRef] [PubMed]

23. Wu, S.; Huang, S.; Ding, J.; Zhao, Y.; Liang, L.; Liu, T.; Zhan, R.; He, X. Multiple microRNAs modulate p21Cip1/Waf1 expression by directly targeting its 3' untranslated region. Oncogene 2010, 29, 2302-2308. [CrossRef] [PubMed]

24. Si, M.L.; Zhu, S.; Wu, H.; Lu, Z.; Wu, F.; Mo, Y.Y. miR-21-mediated tumor growth. Oncogene 2007, 26, 2799-2803. [CrossRef]

25. Cao, H.; Huang, S.; Liu, A.; Chen, Z. Up-regulated expression of miR-155 in human colonic cancer. J. Cancer Res. Ther. 2018, 14, 604-607.

26. Zhu, X.; Wu, L.; Yao, J.; Jiang, H.; Wang, Q.; Yang, Z.; Wu, F. MicroRNA let-7c inhibits cell proliferation and induces cell cycle arrest by targeting CDC25A in human hepatocellular carcinoma. PLoS ONE 2015, 10, e0124266. [CrossRef]

27. Cimmino, A.; Calin, G.A.; Fabbri, M.; Iorio, M.V.; Ferracin, M.; Shimizu, M.; Wojcik, S.E.; Aqeilan, R.I.; Zupo, S.; Dono, M.; et al. miR-15 and miR-16 induce apoptosis by targeting BCL2. Proc. Natl. Acad. Sci. USA 2005, 102, 13944-13949. [CrossRef]

28. Dou, H.; Shen, R.; Tao, J.; Huang, L.; Shi, H.; Chen, H.; Wang, Y.; Wang, T. Curcumin suppresses the colon cancer proliferation by inhibiting Wnt/ß-catenin pathways via miR-130a. Front. Pharmacol. 2017, 8, 877. [CrossRef]

29. Tili, E.; Michaille, J.J.; Adair, B.; Alder, H.; Limagne, E.; Taccioli, C.; Ferracin, M.; Delmas, D.; Latruffe, N.; Croce, C.M. Resveratrol decreases the levels of miR-155 by upregulating miR-663, a microRNA targeting JunB and JunD. Carcinogenesis 2010, 31, 1561-1566. [CrossRef]

30. Kumazaki, M.; Noguchi, S.; Yasui, Y.; Iwasaki, J.; Shinohara, H.; Yamada, N.; Akao, Y. Anti-cancer effects of naturally occurring compounds through modulation of signal transduction and miRNA expression in human colon cancer cells. J. Nutr. Biochem. 2013, 24, 1849-1858. [CrossRef]

31. Tsang, W.P.; Kwok, T.T. Epigallocatechin gallate up-regulation of miR-16 and induction of apoptosis in human cancer cells. J. Nutr. Biochem. 2010, 21, 140-146. [CrossRef] [PubMed]

32. Riffo-Campos, Á.L.; Riquelme, I.; Brebi-Mieville, P. Tools for sequence-based miRNA target prediction: What to choose? Int. J. Mol. Sci. 2016, 17, 1987. [CrossRef] [PubMed]

33. Siegel, R.L.; Miller, K.D.; Jemal, A. Cancer statistics, 2016. CA Cancer J. Clin. 2016, 66, 7-30. [CrossRef] [PubMed]

34. Li, Y.H.; Niu, Y.B.; Sun, Y.; Zhang, F.; Liu, C.X.; Fan, L.; Mei, Q.B. Role of phytochemicals in colorectal cancer prevention. World J. Gastroenterol. 2015, 21, 9262-9272. [CrossRef] [PubMed]

35. Chun, K.S.; Kim, E.H.; Lee, S.; Hahm, K.B. Chemoprevention of gastrointestinal cancer: The reality and the dream. Gut Liver 2013, 7, 137-149. [CrossRef] [PubMed] 
36. Russo, M.; Spagnuolo, C.; Tedesco, I.; Russo, G.L. Phytochemicals in cancer prevention and therapy: Truth or dare? Toxins 2010, 2, 517-551. [CrossRef] [PubMed]

37. Li, Y.; Kong, D.; Wang, Z.; Sarkar, F.H. Regulation of microRNAs by natural agents: An emerging field in chemoprevention and chemotherapy research. Pharm. Res. 2010, 27, 1027-1041. [CrossRef]

38. Phuah, N.H.; Nagoor, N.H. Regulation of microRNAs by natural agents: New strategies in cancer therapies. Biomed. Res. Int. 2014, 2014, 804510. [CrossRef]

39. Ferry, S.; Matsuda, M.; Yoshida, H.; Hirata, M. Inositol hexakisphosphate blocks tumor cell growth by activating apoptotic machinery as well as by inhibiting the Akt/NFkappaB-mediated cell survival pathway. Carcinogenesis 2002, 23, 2031-2041. [CrossRef]

40. Corrêa, T.A.; Rogero, M.M. Polyphenols regulating microRNAs and inflammation biomarkers in obesity. Nutrition 2019, 59, 150-157. [CrossRef]

41. Owen, R.W.; Weisgerber, U.M.; Spiegelhalder, B.; Bartsch, H. Faecal phytic acid and its relation to other putative markers of risk for colorectal cancer. Gut 1996, 38, 591-597. [CrossRef] [PubMed]

42. Liu, J.; Huang, W.H.; Yang, H.X.; Luo, Y. Expression and function of miR-155 in breast cancer. Biotechnol. Biotechnol. Equip. 2015, 29, 840-843. [CrossRef]

43. Chen, Z.; Ma, T.; Huang, C.; Hu, T.; Li, J. The pivotal role of microRNA-155 in the control of cancer. J. Cell. Physiol. 2014, 229, 545-550. [CrossRef] [PubMed]

44. He, B.; Gao, S.Q.; Huang, L.D.; Huang, Y.H.; Zhang, Q.Y.; Zhou, M.T.; Shi, H.Q.; Song, Q.T.; Shan, Y.F. MicroRNA-155 promotes the proliferation and invasion abilities of colon cancer cells by targeting quaking. Mol. Med. Rep. 2015, 11, 2355-2359. [CrossRef] [PubMed]

45. Liu, N.; Jiang, F.; Han, X.Y.; Li, M.; Chen, W.J.; Liu, Q.C.; Liao, C.X.; Lv, Y.F. MiRNA-155 promotes the invasion of colorectal cancer SW-480 cells through regulating the Wnt/ $\beta$-catenin. Eur. Rev. Med. Pharmacol. Sci. 2018, 22, 101-109. [PubMed]

46. Yang, L.; Li, L.; Ma, J.; Yang, S.; Zou, C.; Yu, X. miRNA and mRNA integration network construction reveals novel key regulators in left-sided and right-sided colon adenocarcinoma. Biomed. Res. Int. 2019, 2019, 7149296. [CrossRef]

47. Kong, W.; Yang, H.; He, L.; Zhao, J.J.; Coppola, D.; Dalton, W.S.; Cheng, J.Q. MicroRNA-155 is regulated by the transforming growth factor $\beta /$ Smad pathway and contributes to epithelial cell plasticity by targeting RhoA. Mol. Cell. Biol. 2008, 28, 6773-6784. [CrossRef]

48. Gironella, M.; Seux, M.; Xie, M.J.; Cano, C.; Tomasini, R.; Gommeaux, J.; Garcia, S.; Nowak, J.; Yeung, M.L.; Jeang, K.T.; et al. Tumor protein 53-induced nuclear protein 1 expression is repressed by miR-155, and its restoration inhibits pancreatic tumor development. Proc. Natl. Acad. Sci. USA 2007, 104, 16170-161705. [CrossRef]

49. Tili, E.; Michaille, J.J.; Wernicke, D.; Alder, H.; Costinean, S.; Volinia, S.; Croce, C.M. Mutator activity induced by microRNA-155 (miR-155) links inflammation and cancer. Proc. Natl. Acad. Sci. USA 2011, 108, 4908-4913. [CrossRef]

50. Svrcek, M.; El-Murr, N.; Wanherdrick, K.; Dumont, S.; Beaugerie, L.; Cosnes, J.; Colombel, J.F.; Tiret, E.; Fléjou, J.F.; Lesuffleur, T.; et al. Overexpression of microRNAs-155 and 21 targeting mismatch repair proteins in inflammatory bowel diseases. Carcinogenesis 2013, 34, 828-834. [CrossRef]

51. O'Connell, R.M.; Chaudhuri, A.A.; Rao, D.S.; Baltimore, D. Inositol phosphatase SHIP1 is a primary target of miR-155. Proc. Natl. Acad. Sci. USA 2009, 106, 7113-7118. [CrossRef] [PubMed]

52. Hornsveld, M.; Dansen, T.B.; Derksen, P.W.; Burgering, B.M.T. Re-evaluating the role of FOXOs in cancer. Semin. Cancer Biol. 2018, 50, 90-100. [CrossRef] [PubMed]

53. Liu, Y.; Ao, X.; Ding, W.; Ponnusamy, M.; Wu, W.; Hao, X.; Yu, W.; Wang, Y.; Li, P.; Wang, J. Critical role of FOXO3a in carcinogenesis. Mol. Cancer 2018, 17, 104. [CrossRef] [PubMed]

54. Gao, Y.; Liu, Z.; Ding, Z.; Hou, S.; Li, J.; Jiang, K. MicroRNA-155 increases colon cancer chemoresistance to cisplatin by targeting forkhead box O3. Oncol. Lett. 2018, 15, 4781-4788. [CrossRef] [PubMed]

55. Semenza, G.L. HIF-1: Mediator of physiological and pathophysiological responses to hypoxia. J. Appl. Physiol. 2000, 88, 1474-1480. [CrossRef]

56. Lee, J.W.; Bae, S.H.; Jeong, J.W.; Kim, S.H.; Kim, K.W. Hypoxia-inducible factor (HIF-1) alpha: Its protein stability and biological functions. Exp. Mol. Med. 2004, 36, 1-12. [CrossRef] 
57. Robertson, E.D.; Wasylyk, C.; Ye, T.; Jung, A.C.; Wasylyk, B. The oncogenic MicroRNA Hsa-miR-155-5p targets the transcription factor ELK3 and links it to the hypoxia response. PLoS ONE 2014, 9, e113050. [CrossRef]

58. Buchwalter, G.; Gross, C.; Wasylyk, B. Ets ternary complex transcription factors. Gene 2004, 324, 1-14. [CrossRef]

59. Kong, S.Y.; Kim, K.S.; Kim, J.; Kim, M.K.; Lee, K.H.; Lee, J.Y.; Oh, N.; Park, J.; Park, J.H.; Heo, S.H.; et al. The ELK3-GATA3 axis orchestrates invasion and metastasis of breast cancer cells in vitro and in vivo. Oncotarget 2016, 7, 65137-65146. [CrossRef]

60. Kapral, M.; Sośnicki, S.; Wawszczyk, J.; Węglarz, L. Influence of inositol hexaphosphate on the expression of selected proliferation markers in IL-1ß-stimulated intestinal epithelial cells. Acta Pol. Pharm. 2014, 71, 987-993.

Sample Availability: Samples of the compounds are not available from the authors.

(C) 2019 by the authors. Licensee MDPI, Basel, Switzerland. This article is an open access article distributed under the terms and conditions of the Creative Commons Attribution (CC BY) license (http://creativecommons.org/licenses/by/4.0/). 